\title{
Embolized Crospovidone (poly[ $N$-vinyl-2-pyrrolidone]) in the Lungs of Intravenous Drug Users
}

\author{
Santhi Ganesan, M.D., Joseph Felo, D.O., Mario Saldana, M.D., Victor F. Kalasinsky, Ph.D., \\ Michael R. Lewin-Smith, M.D., Joseph F. Tomashefski, Jr, M.D. \\ Department of Pathology, MetroHealth Medical Center and Case Western Reserve University School of \\ Medicine (SG, JFT) and Cuyahoga County Coroner's Office (JF), Cleveland, Ohio; Department of Pathology, \\ Cedars Medical Center and University of Miami (MS), Miami, Florida; and Armed Forces Institute of \\ Pathology (VFK, MRL-S), Washington, D.C.
}

Crospovidone is an insoluble polymer of $\mathrm{N}$-vinyl-2pyrrolidone that is used as a disintegrant in pharmaceutical tablets. It can potentially embolize to the lung when aqueous tablet suspensions are injected intravenously. In this report, we identified embolized crospovidone in autopsy-derived lung tissue from three adult IV drug users, 1 man and 2 women, whose ages respectively were 27,38 , and 40 years. Suspected crospovidone was compared with pharmaceutical-grade crospovidone by means of histochemical stains, transmission electron microscopy, and infrared spectroscopy. Similar particles were also observed by light microscopy in a 4-mg tablet of hydromorphone, a preparation prescribed to two of the patients. Two patients had sickle cell disease and were taking methadone and/or hydromorphone for pain management; the third was receiving parenteral hyperalimentation after small bowel resection. Crospovidone appeared as deeply basophilic, coral-like particles within pulmonary arteries and in extravascular foreign-body granulomas. Intrapulmonary crospovidone stained similarly to the pure substance, including intense staining with mucicarmine, Congo red, and Masson trichrome. With Movat pentachrome stain, both intravascular and purified crospovidone appeared orange-yellow, whereas most interstitial particles associated with giant cells stained blue-green. Alcian blue failed to stain intravascular or purified crospovidone but

\footnotetext{
Copyright () 2003 by The United States and Canadian Academy of Pathology, Inc.

VOL. 16, NO. 4, P. 286, 2003 Printed in the U.S.A.

Date of acceptance: January 15, 2003.

The opinions or assertions contained herein are the private views of the authors and are not to be construed as official or as reflecting the views of the US Department of the Army or the US Department of Defense. Address reprint requests to: Joseph F. Tomashefski Jr, M.D., Department of Pathology, MetroHealth Medical Center, 2500 MetroHealth Drive, Cleveland, OH 44109-1998; fax: 216-778-7112; e-mail: jtomashefski@metrohealth.org.
}

DOI: $10.1097 / 01 . M P .0000062653 .65441 . D A$ strongly decorated some phagocytized particles. Ultrastructurally, both purified powder and tissue deposits of crospovidone appeared as irregular, electron dense, laminated, and finely granular material. Intrapulmonary crospovidone was associated with inflammatory cells and exhibited degenerative changes. By infrared spectroscopy, crospovidone in tissue had the same spectral characteristics as pharmaceutical grade crospovidone and the library reference, polyvinylpyrrolidone (PVP). We conclude that crospovidone contributes to pulmonary vascular injury in some persons who illicitly inject pharmaceutical tablets. It is readily identifiable histologically and distinguishable from other tablet constituents, such as cornstarch, talc, and microcrystalline cellulose. The variable staining with Alcian blue and Movat suggests that crospovidone is altered in vivo by the inflammatory response.

KEY WORDS: Crospovidone, Foreign body emboli, Intravenous drug use, $N$-vinyl-2-pyrrolidone, Polyvinylpyrrolidone.

Mod Pathol 2003;16(4):286-292

Pharmaceutical tablets typically consist of active ingredients and a variety of insoluble filler substances, such as talc, microcrystalline cellulose, and cornstarch, which provide bulk and impart physical properties to tablet preparations (1). Pulmonary foreign body granulomatosis caused by the embolization of these filler materials occurs when aqueous suspensions of tablets intended for oral consumption are injected intravenously (1-3).

Some of the agents used in this manner, either alone or in combination, include methadone hydrochloride, tripelennamine hydrochloride (Pyribenzamine), methylphenidate (Ritalin), and pentazocine (Talwin; 3-6). Pulmonary angiothrombotic granulomatosis caused by talc, cornstarch and/or microcrys- 
talline cellulose has been widely reported, with an emphasis on the subsequent development of fatal pulmonary hypertension and cor pulmonale (3, 7-11). Other less well-recognized tablet excipients that have injurious potential include magnesium stearate and siliciumoxid (silicon dioxide; 1 ).

We have recently identified, in autopsy-derived lung tissue of three intravenous drug users, a distinctive embolic material, crospovidone (a polyvinylpyrrolidone), that is an important disintegrant in pharmaceutical tablets (12-15). Crospovidone has not generally been emphasized, or recognized by pathologists, as a cause of pulmonary angiothrombosis and foreign body granulomatosis. In this report we characterize the morphologic, histochemical, spectroscopic, and ultrastructural features that facilitate the recognition and identification of crospovidone in tissue sections and describe the inflammatory response and lung vascular remodeling resulting from the intravenous injection of this substance.

\section{METHODS}

We reviewed the clinical data, autopsy protocols, and microscopic slides of the three subjects included in this study. A review of slides from all cases of fatal hydromorphone toxicity from 1985 to 2001 that were on file at the Cuyahoga County Coroner's office failed to disclose any other cases of similar pulmonary foreign body emboli.

Embolized material seen in the lungs of all three patients was suspected to be crospovidone, a known constituent of certain preparations of hydromorphone tablets (Roxane Corp.). Two patients had been prescribed 4-mg hydromorphone tablets for pain management. In order to verify the identity of the embolized substance, we first recognized similar particles in an aqueous suspension of a 4-mg hydromorphone tablet (Roxane Corp.). The morphology and staining properties of the material in tissue sections were then compared with those of purified crospovidone powder (Polyplasdone XL) obtained from the manufacturer (12).

The crospovidone powder was embedded in a paraffin block from which 5 - $\mu$ m-thick sections were cut and respectively stained with Movat pentachrome, Alcian blue, mucicarmine, periodic acidSchiff with diastase predigestion (PAS/D), Masson trichrome, Gomori methenamine silver (GMS), Congo red, von Kossa, Alizarin red, Gram, Prussian blue, and Fontana-Masson. Representative sections of lung that contained suspected crospovidone from each patient were histochemically stained as listed above.

A small amount of pharmaceutical-grade crospovidone powder and a fragment of formalin-fixed lung tissue from Patient 1 were washed with glutaraldehyde, postfixed in $1 \%$ osmium tetroxide, stained en bloc with $1 \%$ aqueous uranyl acetate, dehydrated with acetone, and embedded in Spurr's resin. The blocks were then thin-sectioned and stained with $1 \%$ uranyl acetate-lead citrate and examined with a transmission electron microscope.

Infrared spectra were obtained by using a Nicolet (ThermoNicolet, Madison, WI) model 860 Fourier transform infrared spectrometer attached to a Nicolet Continuum infrared microscope. Specimens approximately $5 \mu \mathrm{m}$ thick were cut from paraffin-embedded crospovidone powder and from formalin-fixed lung tissue (Case 1), then mounted on the aluminum-coated glass slides. A reflective objective $(32 \times)$ was used to focus the infrared light onto the sections. Infrared spectra were obtained as the light passed through the sample, reflected off the aluminum surface, and passed through the sample a second time before being directed to a liquid nitrogen-cooled mercury-cadmium-telluride (MCT) detector. Spectra were recorded at $4-\mathrm{cm}^{-1}$ spectral resolution, and sample spectra were compared with background spectra obtained from blank regions on the slide and expressed as a ratio. Adjustable apertures (between 20 and $50 \mu \mathrm{m}$ in size) were used in the microscope to localize the infrared beam to the areas of interest, and 128 scans were co-added to reduce noise levels and provide adequate spectral quality. The spectrometer was purged with dry air to minimize the effects of absorptions caused by atmospheric water vapor and carbon dioxide. The measured infrared spectra were compared with those of authentic samples stored in commercial spectral libraries and obtained in our laboratories.

\section{REPORT OF CASES}

\section{Case 1}

A 40-year-old African-American woman with sickle cell disease and frequent sickle cell crises died 2 weeks after hospitalization for Enterococcus cloacae sepsis. Her hospital course included respiratory failure requiring supplemental oxygen and mechanical ventilation. Echocardiogram revealed an elevated pulmonary artery pressure of $69 \mathrm{~mm}$ Hg. The patient was taking hydromorphone and methadone, as well as multiple other medications for pain control, and was on a patient-controlled anesthesia pump.

\section{Case 2}

A 27-year-old African-American man with sickle cell disease and dilated cardiomyopathy underwent surgical repair of a ruptured aortic aneurysm 7 years before death. As a result of his aneurysm, he was rendered paraplegic, with a neurogenic bladder, decubitus ulcers, chronic pyelonephritis, and 
chronic osteomyelitis. A peripherally inserted central catheter (PICC) had been placed for long-term antibiotic and analgesic therapy. At the time of his sudden death, the patient's pain medications consisted of a 75-mg Duragesic patch and oral 4-mg hydromorphone tablets. The patient had a long history of intravenous drug use. At the scene of his death, the patient was found with a syringe, containing clear liquid with white particles, inserted in the PICC line. After toxicology analysis, the cause of his death was determined to be acute intoxication by the combined effects of hydromorphone, oxycodone, and promethazine.

\section{Case 3}

A 38-year-old woman, who was on hyperalimentation after extensive small bowel resection, died suddenly. Her prescribed medications included propoxyphene and Percocet. There was no clinical history of intravenous drug use. The cause of her death was determined to be pulmonary granulomatosis and ischemic colitis. Postmortem toxicology studies were positive for propoxyphene.

\section{RESULTS}

Complete autopsy data from all three subjects indicated combined lung weights of 1210, 950, and $1400 \mathrm{~g}$, respectively. Macroscopically, the lungs of subjects 1 and 2 exhibited pleural adhesions. In Subjects 1 and 3, the parenchyma was congested and/or edematous. Subject 1 also exhibited mild centriacinar emphysema, scattered thromboemboli, and peripheral areas of induration. Subject 2 had normal-appearing, crepitant lung parenchyma. Total cardiac weights (right ventricular wall thickness) were, respectively, $550 \mathrm{~g}(0.8 \mathrm{~cm}), 520 \mathrm{~g}(0.5$ $\mathrm{cm})$, and $350 \mathrm{~g}(0.35 \mathrm{~cm})$.

Upon microscopic examination, all three subjects demonstrated extensive pulmonary angiothrombosis and angiocentric foreign body granulomas associated with birefringent, rodlike crystals having the staining properties of microcrystalline cellulose (3). In addition to the cellulose particles, there were abundant, non-birefringent, deeply basophilic, irregular, coral-like structures measuring $\leq 100 \mu \mathrm{m}$ in maximum dimension (Fig. 1). These particles were

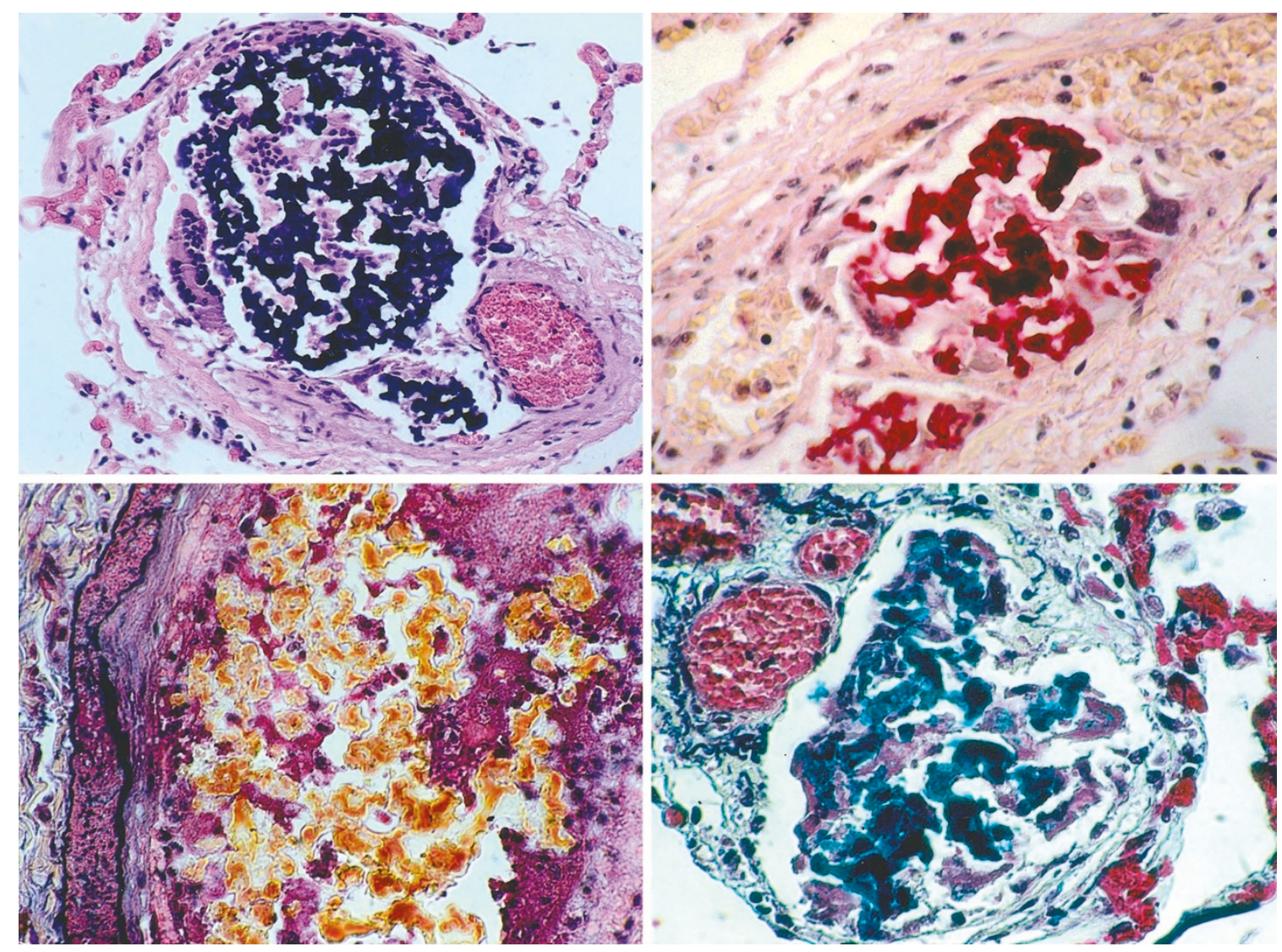

FIGURE 1. Left upper, embolized crospovidone appears as deeply basophilic coral-like particles associated with a foreign body giant cell reaction. The vascular lumen has been greatly restricted (H\&E; original magnification, $160 \times$ ). Right upper, crospovidone (deep red) in a recanalized thromboembolus (mucicarmine; original magnification, $400 \times$ ). Left lower, intravascular crospovidone (yellow-orange particles) associated with recent thrombus, in muscular pulmonary artery (Movat pentachrome; original magnification, 250×). Right lower, crospovidone (blue-green particles) and associated foreign body granuloma have partially destroyed the vascular elastica of a non-muscular pulmonary artery (Movat pentachrome; original magnification, $250 \times)$. 
associated with an intravascular and perivascular foreign body giant cell reaction in all three patients (Fig. 1). In Subject 2, similar particles were present in a subcutaneous abscess, and in Subjects 2 and 3, they lay freely enmeshed in fibrin within pulmonary arterial lumens, indicative of recent injection (Fig. 1). In Subject 3, rare particles were additionally identified in small, nonmuscular, myocardial blood vessels.

Particles present in the histologic sections of pure crospovidone powder resembled similar material in the wet preparation of the 4-mg hydromorphone tablet and were morphologically and histochemically similar to the particles in the lung (Figs. 1-2; Table 1). Crospovidone was most vividly demonstrated by H\&E (violet-blue), mucicarmine (brilliant red), and Congo red (red-brown; Fig. 1). Both von Kossa and alizarin red stains for calcium were negative, although a weak salmon-pink color was apparent with alizarin red. Two patterns of staining were observed with Alcian blue and Movat stains. Phagocytized particles within foreign body giant cells tended to stain, respectively, blue or bluegreen with Alcian blue or Movat, whereas crospovidone powder and recently injected material within arteries was red with Alcian blue and appeared yellow-orange with Movat pentachrome stain (Fig. 1). Transitional staining from red to blue (Alcian blue) or orange to blue-green (Movat) was observed within foreign-body granulomas. Bright red staining by nuclear fast red counterstain was also apparent in the Prussian blue and FontanaMasson stains. With PAS/D, particles were deep blue-gray. GMS staining was weak, with focal brown to gray coloration in both lung sections and in sections of crospovidone powder.

Ultrastructurally, both crospovidone powder and intrapulmonary crospovidone appeared electron dense with a finely granular, mosaic, lamellar pattern imparting a "scrolled" appearance (Fig. 3). Particles that were associated with a foreign body re- action had frayed, deeply scalloped indentations, within which resided inflammatory cells (Fig. 3).

The infrared spectra were obtained from the regions corresponding to those indicated in the H\&Estained histologic section of lung (Fig. 4). Both birefringent, crystalline, nonstaining particles and non-birefringent, coral-like, basophilic foreign material were analyzed. A computerized search of a reference collection of infrared spectra revealed that the spectra obtained from the tissue very closely matched those of cellulose and polyvinylpyrrolidone (PVP), respectively. In Figure 4, the birefringent material in the region marked " $\mathrm{A}$ " is a cellulose derivative, and the regions marked "B" and "C" contain PVP along with tissue protein. The infrared spectra obtained from a section of paraffin-embedded crospovidone was identical to that obtained in regions " $\mathrm{B}$ " and " $\mathrm{C}$ " and also very closely matched the reference spectrum of PVP (Figs. 2,4).

\section{DISCUSSION}

Crospovidone is a synthetic, insoluble homopolymer of $N$-vinyl-2-pyrrolidone, formed by a unique, simultaneous polymerization and cross-linking reaction ("popcorn" polymerization) of vinyl pyrrolidone (12-14). On scanning electron microscopy, crospovidone particles have a convoluted, spongelike appearance $(12,15)$. Its cross-linked structure provides a large absorptive surface and tremendous hygroscopicity that imparts a rapid swelling rate, making crospovidone an excellent tablet disintegrant. Swelling of crospovidone by slightly soluble drugs also results in a subsequent high release rate of the drug in aqueous media (14). In its purified form, crospovidone is a white powder that is chemically inert, essentially nontoxic, and not absorbed through the gastrointestinal tract. According to one pharmaceutical manufacturer (Roxane Corp.) and
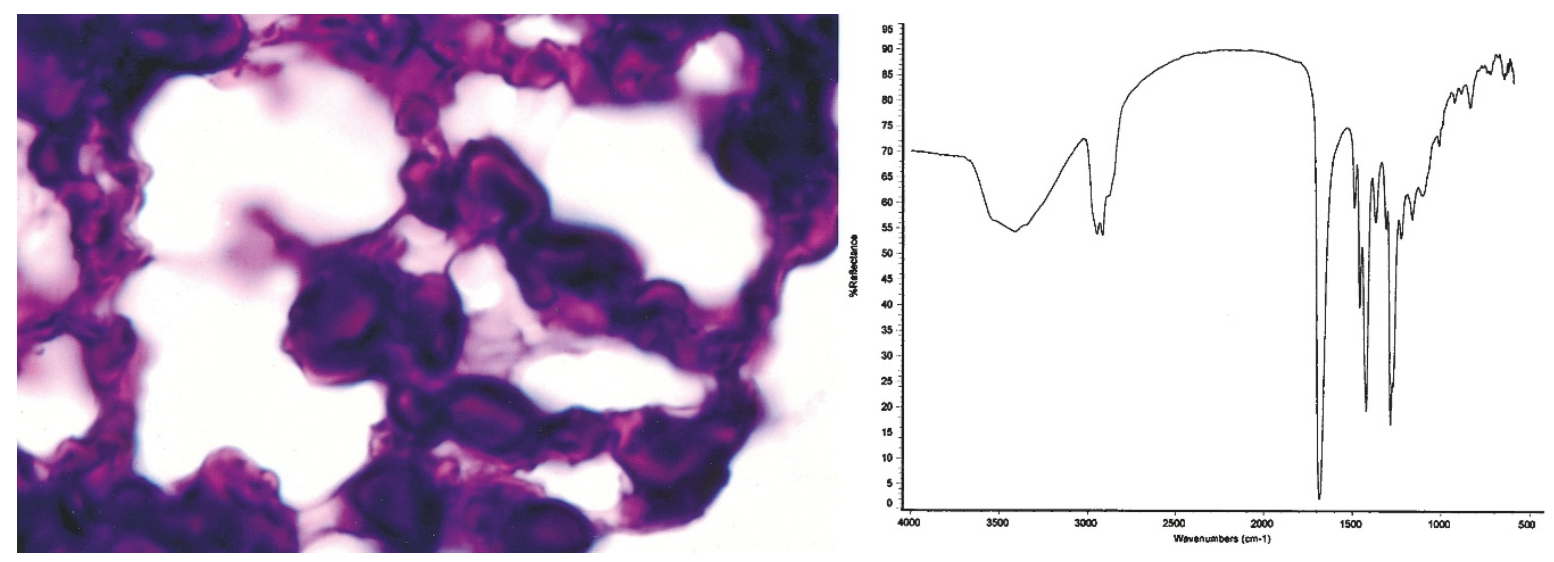

FIGURE 2. Left, powdered crospovidone (Polyplasdone XL; H\&E; original magnification, $480 \times$ ). Right, infrared spectrum. 


\begin{tabular}{|c|c|c|}
\hline Stain & $\begin{array}{c}\text { Form/Location } \\
\text { of Material* }\end{array}$ & Result \\
\hline $\mathrm{H} \& \mathrm{E}$ & $\mathrm{I}, \mathrm{FB}, \mathrm{P}$ & Violet-blue \\
\hline Mucicarmine & $\mathrm{I}, \mathrm{FB}, \mathrm{P}$ & Bright red \\
\hline Congo red & I, FB, P & Red-brown \\
\hline Masson trichrome & $\mathrm{I}, \mathrm{FB}, \mathrm{P}$ & Red-brown/blue \\
\hline \multirow[t]{2}{*}{ Alcian blue } & $\mathrm{I}, \mathrm{FB}, \mathrm{P}$ & Red \\
\hline & FB & Blue \\
\hline \multirow[t]{2}{*}{ Movat pentachrome } & $\mathrm{I}, \mathrm{FB}, \mathrm{P}$ & Yellow-orange \\
\hline & $\mathrm{FB}$ & Blue-green \\
\hline Gomori methenamine silver & I, FB, P & Brown to grey \\
\hline PAS/D & $\mathrm{I}, \mathrm{FB}, \mathrm{P}$ & Blue-grey \\
\hline Other stains $^{+}$ & $\mathrm{I}, \mathrm{FB}, \mathrm{P}$ & Negative \\
\hline
\end{tabular}

\footnotetext{
* $\mathrm{I}=$ intravascular; $\mathrm{FB}=$ foreign-body granuloma; $\mathrm{P}=$ purified powder, in vitro.
}

${ }^{+}$Other stains = von Kossa, Alizarin red, Gram, Prussian blue, Fontana-Masson.

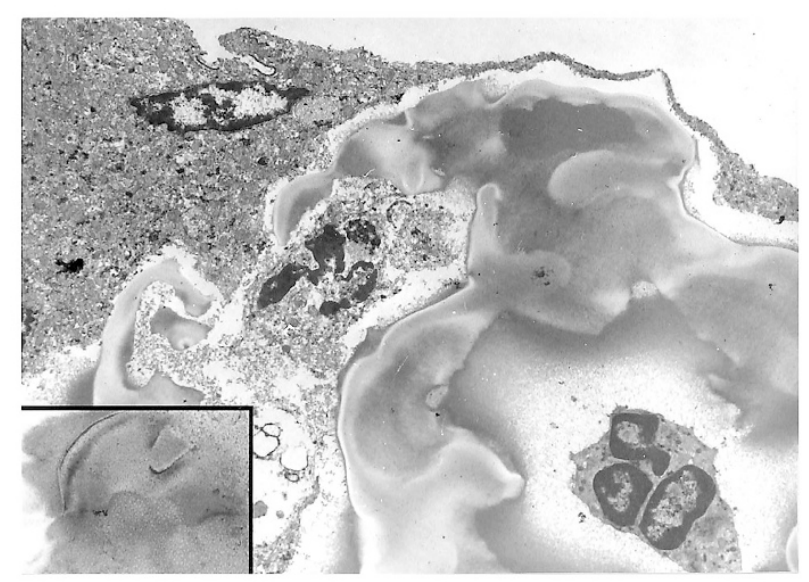

FIGURE 3. Intrapulmonary crospovidone (Subject 1). The crospovidone particle is deeply scalloped, fragmented, and degenerated. A foreign body giant cell (upper left) extends a cytoplasmic process around the particle. Neutrophils are present adjacent to the material (TEM; magnification, $5380 \times$ ). Inset. Ultrastructure of pure, pharmaceutical grade crospovidone powder (Polyplasdone XL). There is a finely granular, mosaic, and lamellar pattern (TEM; magnification, 10,175×).

confirmed by our direct observation of a wetmount tablet suspension, crospovidone is a component in some 4-mg hydromorphone tablets, which had been prescribed to two of the patients in this study. Because of its widespread pharmaceutical application, however, crospovidone is a likely constituent of other tablet preparations intended for oral consumption that might also be subject to intravenous administration.

The identity of crospovidone particles in lung tissue of the individuals in this study was confirmed by histochemical, ultrastructural, and spectroscopic conformity with pharmaceutical-grade crospovidone. Because of its basophilic, irregular appearance, crospovidone particles were initially considered to represent dystrophic calcification. However, alizarin red and von Kossa stains for calcium were negative. Crospovidone is readily distinguished from other tablet additives such as talc, cornstarch, and microcrystalline cellulose, which

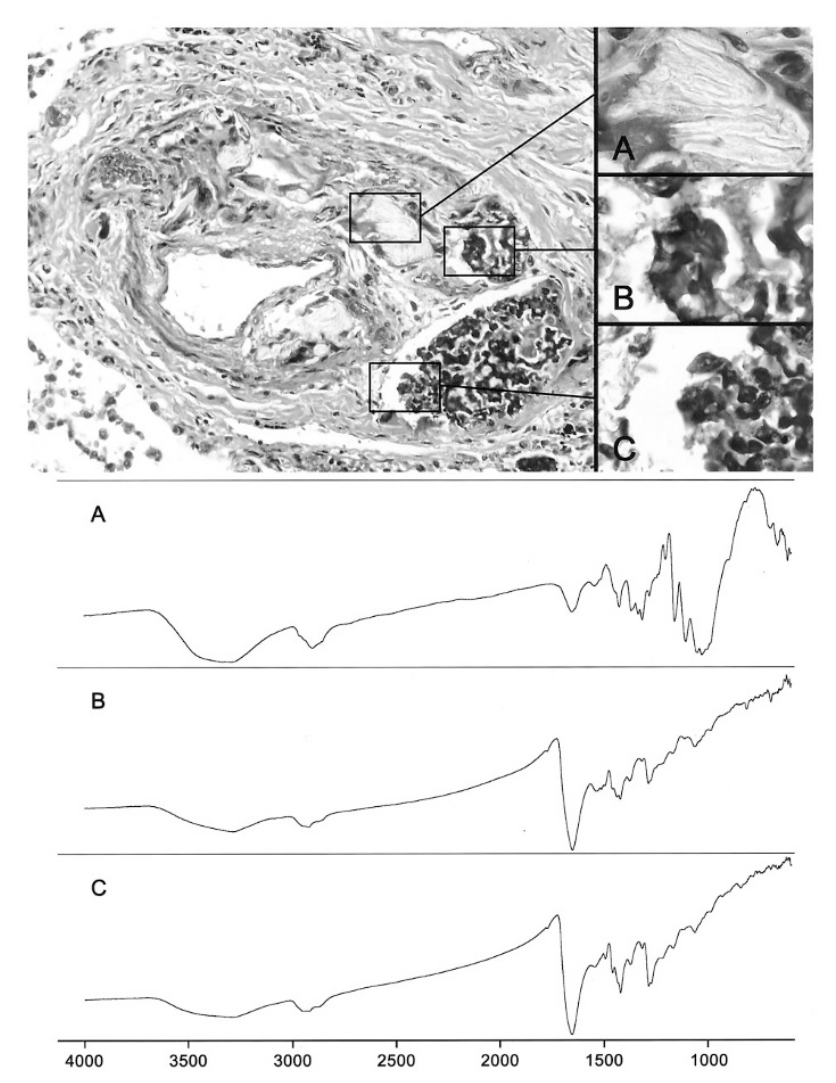

FIGURE 4. Upper, occluded and recanalized pulmonary artery (Subject 1), showing cellulose (Inset $\boldsymbol{A}$ ) and polyvinylpyrrolidone/crospovidone (Insets $\boldsymbol{B}$ and $\boldsymbol{C}$ ) in areas of foreign body giant cell reaction. (H\&E; original magnification, $50 \times$; Insets $\mathrm{A}, \mathrm{B}$, and C, original magnifications, $480 \times$ ). Lower, infrared spectra from Insets A (cellulose), B, and C (polyvinylpyrrolidone), wavenumber in $\mathrm{cm}^{-1}$ abscissa.

are typically colorless with $\mathrm{H} \& \mathrm{E}$ staining and brightly birefringent, with characteristic appearances under polarized light (2). The histochemical staining profile, including an intense reaction with mucicarmine and Congo red stains, and lack of red-violet staining with periodic acid-Schiff, provides reliable confirmation of crospovidone in histologic sections.

Crospovidone contributes to vascular injury by causing angiothrombosis, foreign-body granuloma- 
tosis, and granulomatous angiitis, similar to the case with other embolized tablet excipients $(3,8)$. Through a process of vascular remodeling, crospovidone may assume an extravascular location (2, 16). In the subjects of this report, the quantity of crospovidone in the lung was exceeded by microcrystalline cellulose, correlating with the relative proportions of the two materials in tablet preparations.

Unlike pure crospovidone powder, phagocytized crospovidone in foreign body giant cells focally stained strongly with Alcian blue and the Alcian blue component of the Movat pentachrome stain. This divergent staining reaction suggests that crospovidone particles are chemically altered by the inflammatory response. The ultrastructural appearance of degenerated particles in association with inflammatory cells supports this interpretation.

Crospovidone is a polymer of vinyl pyrrolidone and therefore represents a variant of polyvinylpyrrolidone. Its unique cross-linked structure imparts histological, physical, and biochemical features that distinguish it from other forms of polyvinylpyrrolidone.

Historically, PVPs have had various uses, including applications as plasma expanders, as resin in hair spray, as a medium for hormones and tincture of iodine, and as a binder in pharmaceutical tablets (17). The molecular weight of PVP ranges widely depending on the polymer chain length of the material in question. PVP infusions with a molecular weight of $<50,000$ undergo rapid renal excretion (18). However, PVP is also chemically stable and is not widely metabolized, leading to rapid accumulation, particularly in the reticuloendothelial system, blood vessels, liver, kidney, and spleen (19). Infiltration of PVP in bone marrow has been reported to be a complication of massive intravenous injection that was associated with severe irreversible anemia and destruction of bone (20).

PVP has previously been recognized as a cause of mucicarminophilic histiocytosis, pseudosarcomatous subcutaneous granuloma, and the inhalational lung disease, thesaurosis (hair-sprayer's lung; 17, 18, 21-24). It imparts a bubbly appearance to histiocytes, which thereby resemble malignant signetring cells $(17,21,25)$. PVP has additionally been reported to mimic congenital mucolipid storage disease in a patient with Munchausen's syndrome (26). Although a small amount of mucoid material was present within granulomas in one of our patients, crospovidone does not have the appearance in tissue of mucicarminophilic histiocytosis. It appears likely, therefore, that the histopathologic features described in mucicarminophilic histiocytosis and similar lesions are associated with non- crospovidone PVPs. The histochemical staining reactions of PVP in mucicarminophilic histiocytosis overlap those of crospovidone, yet differ in their strong staining with GMS and Fontana-Masson. Ultrastructurally, PVP in mucicarminophilic histiocytosis appears as a finely granular material with dense aggregates that is easily distinguishable from the mosaic, lamellar structure of crospovidone (17, 22, 25).

PVP was extracted from subcutaneous tissue and identified by infrared spectroscopy in a previous study (22). In our study, infrared microspectroscopy was used to identify and localize polyvinylpyrrolidone and cellulose in formalin-fixed, paraffin-embedded tissue sections. The infrared spectra of polyvinylpyrrolidone in that previous study and in our study are similar (22). The infrared spectrum of crospovidone is indistinguishable from other forms of polyvinylpyrrolidone. However, crospovidone can be differentiated from other forms of PVP in tissue sections by combining the infrared spectrum with the observed histologic and histochemical characteristics. In a study of x-ray photoelectron spectra, there were subtle differences between the spectra of crospovidone and other forms of PVP (14). Additional studies may determine whether minor variations in the infrared spectra obtained from various forms of PVP in tissue can be used to distinguish different PVP polymers.

The deeply basophilic property of crospovidone in H\&E-stained sections may suggest the potassium binding resin, sodium polystyrene sulfonate (Kayexalate), which is occasionally aspirated into the lung (27). Kayexalate, however, is a much more angulated particle, with a glassy appearance, and is confined to airspaces where it elicits organizing pneumonia (27). Confusion with Kayexalate conceivably could occur in individuals who aspirate crospovidone-containing tablets.

In summary, crospovidone is a readily recognizable constituent of pharmaceutical tablets that contributes to pulmonary vascular injury in the lungs of some individuals who inject aqueous suspensions of tablet preparations. The intravascular presence of crospovidone provides yet another histological marker of intravenous drug use. The long-term effects of crospovidone within the lung are unknown.

Acknowledgments: The authors acknowledge the valuable discussion and insight provided by Frank B. Johnson, M.D., and his review of the manuscript. Meghan Lehmann, R.Ph., Pharm. D., provided pharmacological advice and resource material. 


\section{REFERENCES}

1. Kringsholm B, Christoffersen P. The nature and the occurrence of birefringent material in different organs in fatal drug addiction. Forensic Sci Int 1987;34:53-62.

2. Tomashefski JF Jr, Hirsch CS. The pulmonary vascular lesions of intravenous drug abuse. Hum Pathol 1980;11:13345.

3. Tomashefski JF Jr, Hirsch CS, Jolly PN. Microcrystalline cellulose pulmonary embolism and granulomatosis. A complication of illicit intravenous injections of pentazocine tablets. Arch Pathol Lab Med 1981;105:89-93.

4. Pare JAP, Fraser RG, Hogg JC, Howlett JG, Murphy SB. Pulmonary "mainline" granulomatosis: talcosis of intravenous methadone abuse. Medicine 1979;58:229-39.

5. Wendt VE, Puro HE, Shapiro J, Matthews W, Wolf PL. Angiothrombotic pulmonary hypertension in addicts: "blue velvet" addiction. JAMA 1964;188:755-7.

6. Lewman LV. Fatal pulmonary hypertension from intravenous injection of methylphenidate (Ritalin) tablets. Hum Pathol 1972;3:67-70.

7. Nan DN, Fernandez-Azala M, Iglesias L, Garcia-Paloma D, Parra JA, Farinas MC. Talc granulomatosis. A differential diagnosis of interstitial lung disease in HIV patients. Chest 2000;118:258-60.

8. Arnett EN, Battle WE, Russo JV, Roberts WC. Intravenous injection of talc-containing drugs intended for oral use. A cause of pulmonary granulomatosis and pulmonary hypertension. Am J Med 1976;60:711-8.

9. Hopkins GB. Pulmonary angiothrombotic granulomatosis in drug offenders. JAMA 1972;221:909-11.

10. Johnston WH, Waisman J. Pulmonary corn starch granulomas in a drug user. Light and electron microscopic study of a case. Arch Pathol 1971;92:196-202.

11. Lamb D, Roberts G. Starch and talc emboli in drug addicts' lungs. J Clin Pathol 1972;25:876-81.

12. Polyplasdone XL. Wayne, NJ: International Specialty Products. Available at: www.isp-pharma.com/library/polyplasdone/polyplasdone.html.

13. Kornblum SS, Stoopak SB. A new tablet disintegrating agent: cross-linked polyvinylpyrrolidone. J Pharm Sci 1973;62:43-9.

14. Carli F, Garbassi F. Characterization of drug loading in crospovidone by x-ray photoelectron spectroscopy. J Pharm Sci 1985;74:963-7.

15. Shah U, Augsburger L. Evaluation of the functional equivalence of Crospovidone NF from different sources. II. Standard performance test. Pharm Dev Technol 2001;6:419-30.
16. Puro HE, Wolf PL, Skirgaudas J, Vazquez J. Experimental production of human "blue velvet" and "red devil" lesions. JAMA 1966;197:1100-2.

17. Kuo T, Hsueh S. Mucicarminophilic histiocytosis: a polyvinylpyrrolidone (PVP) storage disease simulating signet-ring cell carcinoma. Am J Surg Pathol 1984;8:419-28.

18. Enzinger FM, Weiss SW. Polyvinylpyrrolidone granuloma. In: Soft tissue tumors. 3rd ed. St. Louis, MO: Mosby-Year Book; 1995. p. 317-8.

19. Hartman FW. Tissue changes following the use of plasma substitutes. AMA Arch Surg 1951;63:728-38.

20. Kuo T-T, Hu S, Huang C-L, Chan H-L, Chang MJW, Dunn P, et al. Cutaneous involvement in polyvinylpyrrolidone storage disease: a clinicopathologic study of five patients, including two patients with severe anemia. Am J Surg Pathol 1997;21:1361-7.

21. Groisman GM, Amar M, Weiner P, Zamir D. Mucicarminophilic histiocytosis (benign signet-ring cells) and hyperplastic mesothelial cells. Two mimics of metastatic carcinoma within a single lymph node. Arch Pathol Lab Med 1998;122: 282-4.

22. Hizawa K, Inaba H, Nakanishi S, Otsuka H, Izumi K. Subcutaneous pseudosarcomatous polyvinylpyrrolidone granuloma. Am J Surg Pathol 1984;8:393-8.

23. Bergmann M, Flance IJ, Cruz PT, Klam N, Aronson PR, Joshi RA, et al. Thesaurosis due to inhalation of hair spray. Report of 12 new cases, including three autopsies. N Engl J Med 1962;266:750-5.

24. Gebbers J-O, Tetzner C, Burkhardt A. Alveolitis due to hairspray. Ultrastructural observations in two patients and the results of experimental investigations. Virchows Arch A Pathol Anat Histol 1979;382:323-38.

25. Hewan-Lowe K, Hammers Y, Lyons JM, Wilcox CM. Polyvinylpyrrolidone storage disease: a source of error in the diagnosis of signet ring cell gastric adenocarcinoma. Ultrastruct Pathol 1994;18:271-8.

26. Bubis JJ, Cohen S, Dinbar J, Hirschhorn B, Szeinberg A, Wolman M. Storage of polyvinylpyrrolidone mimicking a congenital mucolipid storage disease in a patient with Munchausen's syndrome. Israel J Med Sci 1975;11:999-1004.

27. Fenton JJ, Johnson FB, Przygodzki RM, Kalasinsky VF, AlDayel F, Travis WD. Sodium polystyrene sulfonate (Kayexalate) aspiration. Histologic appearance and infrared microspectrophotometric analysis of two cases. Arch Pathol Lab Med 1996;120:967-9. 